Miembro de Número de la Academia Nacional de Medicina.

ISSN 0001-6002/2007/49/2/79-80 Acta Médica Costarricense, (O2007 Colegio de Médicos y Cirujanos

\section{Comentarios sobre el libro de Michael Porter y Elizabeth Olmedted Teisberg, "Redefining Health Care"}

\author{
Carlos Arrea-Baixech
}

El libro recientemente publicado por Michael Porter y Elizabeth Olmedted Teisberg, titulado "Redefining Health Care", que fuera la base de la conferencia que presenté ante la Academia Nacional de Medicina, merece un lugar en esta revista. Los autores son profesores de administración, el primero de la Universidad de Harvard y la segunda de la Universidad de Virginia, líderes mundiales en competitividad e innovación. Por 10 años han estudiado el Sistema de Salud de los Estados Unidos y todos los comentarios se refieren a este.

Se trata del sistema de salud más caro del mundo, con un gasto de $\$ 5.500$ por persona al año, en tanto otros, como los de Alemania, Canadá, Inglaterra, y Japón, gastan menos de $\$ 3.000$, además, crece un $6 \%$ anual. Es de esperar que siendo tan caro obtenga los mejores resultados, sin embargo, las cifras muestran todo lo contrario. A pesar de gastar un $14.2 \%$ de su producto interno bruto, la esperanza de vida, de 79 años, es inferior a la de Japón, que tiene 82.3 años y solo gasta un $6 \%$ del PIB. Llama la atención que el 35\% de los estadounidenses se encuentran inconformes con el sistema y el $45 \%$, desprotegidos, ya que al ser privado y tan caro, no lo pueden pagar.

La cantidad de errores médicos es alarmante y en lugar de disminuir, crece, lo que causa prolongados internamientos y lesiones que con frecuencia son permanentes. También son causa de muertes, las cuales, de acuerdo con dos estudios realizados uno en 1988 y otro en 2002, van en aumento, pasando de 96.000 en el primero, a 200.000 en el segundo. Esto coloca los errores médicos en el sexto lugar en 1988 y en el tercero en 2002, como una de las principales causas de muerte en ese país, apenas superada por las enfermedades cardiovasculares y los tumores malignos.

El tiempo que están obligados a invertir los médicos en completar formularios y hacer funciones administrativas ha aumentado a tal extremo, que en algunas áreas como las emergencias, llega al $50 \%$, lo que significa que la mitad de sus tareas se dirigen a acciones que no aportan ningún beneficio al paciente.

Todos los participantes manifiestan inconformidad con el sistema y el gobierno ha perdido el control.

Las propuestas para corregir estos problemas se vinculan con dos campos, fundamentalmente: la forma de abordar las enfermedades para ofrecerle más beneficios al paciente y los cambios que deben efectuar las distintas entidades vinculadas con la prestación de los servicios.

Creen que se debe tratar por todos los medios, de brindar lo que llaman "valores para el paciente", definidos como la mejor medicina, al menor precio posible. Íntimamente relacionada con este concepto, plantean una modificación en el abordaje de las enfermedades. En lugar de hacerlo como se hizo desde la mitad del siglo pasado, por especialistas que trabajan independientemente y con poca comunicación entre ellos -lo que ha fragmentando la medicina al crear gran incertidumbre en el paciente y tener que confrontar opiniones a veces antagónicas-, hacerlo por ciclos de entidades médicas. Consideran entidades médicas, por ejemplo, la osteoartritis de cadera, cuyo ciclo comprende la prevención, el diagnóstico, el tratamiento -que incluye la cirugía- y la rehabilitación. 
Otro aspecto que determinan fundamental es la competitividad de resultados. Cada ciclo de las distintas entidades médicas debe estar al tanto de sus resultados y hacerlos del conocimiento de médicos y pacientes, para que con base en ellos se escojan el sitio y los profesionales que mejor los obtienen.

La información bien orientada a los resultados de cada ciclo es muy importante para que funcionen las propuestas y haya competitividad que aporte beneficios al paciente.

Proponen también modificaciones en la forma de actuar de los participantes en el proceso:

Los pacientes deben ser mejor informados de los resultados.

Los médicos deben pensar más en los valores para el paciente y menos en protocolos o sistemas que no fueron diseñados teniendo en cuenta tal premisa.

Los hospitales no se deben mercadear como hoteles, sino a partir de los resultados obtenidos tras los ciclos que puedan ofrecer con excelencia.

Es preferible que los médicos y hospitales hagan pocas cosas bien, que todo de manera regular o inadecuada.

Los hospitales no deben hacer de todo, sino ofrecer servicios únicamente en lo que puedan conseguir buenos resultados.
Los hospitales rurales tienen como primera obligación las emergencias, usando el sistema que han puesto en práctica los ejércitos: Brindar solo servicios en los que puedan ofrecer buenos resultados, estabilizar y referir a los centros especializados a quienes lo ameriten; esta función de referencia se considera primordial y debe organizarse bien; en ocasiones, usando los medios de comunicación disponibles, pueden viajar los exámenes y no los pacientes. $\mathrm{Su}$ segunda función debe ser la medicina preventiva y de rutina; no se justifica referir una gripe o un quiste sebáceo .

Las compañías de tecnología y farmacéuticas deben pensar más en los beneficios que puedan transmitir a los pacientes que en sus ganancias; algo difícil de alcanzar en este mundo tan competitivo y voraz .

A los estudiantes de medicina hay que enseñarlos a trabajar en equipo. La comparación con los deportes es de gran enseñanza, pues hay varios colectivos que tienen las mejores estrellas y no ganan partidos.

En términos generales, este extenso libro de más de 500 páginas es una lectura que debe recomendarse, a pesar de no haber sido escrito por médicos, porque como he tratado de exponer muy brevemente, comprende conceptos interesantes.

Adolece de que le concede poco tiempo y espacio a la medicina preventiva, que es el alma de cualquier sistema de salud. 